\title{
A BASE-ISOLATION DESIGN USING SPHERICALLY-ENDED ROLLERS AND TELESCOPIC SHOCK ABSORBERS
}

\author{
L.T. Pham
}

\begin{abstract}
The seismic strength of 16 valve damping resistors in the HVDC transmission network of the Electricity corporation of New Zealand (Electricorp) were upgraded to current design requirements using a baseisolation design. This paper discusses the design, the prototype-testing and outlines briefly the usefulness and limitations of spherically-ended rollers as a base-isolation support.
\end{abstract}

\section{INTRODUCTION}

Valve damping resistors are an essential component of the HVDC transmission equipment. There are a total of 16 resistors, 8 are located at Haywards Substation in the North Island and the other 8 are at Benmore Power station in the South Island.

The resistor was designed in the early 1960 's using a horizontal seismic factor of $0.25 \mathrm{~g}$. However, later calculations, taking into account the dynamic amplification, have shown that the resistor can experience up to $1.5 \mathrm{~g}$ seismic acceleration at its centre of gravity in a design level earthquake (e.g El Centro $1940 \mathrm{~N}-\mathrm{S}$ ). It was estimated that fracture of the porcelain column would be likely with induced acceleration reaching about $0.75 \mathrm{~g}$.

Earthquake damage to the resistors must be avoided as the HVDC link is a crucial component of the power supply in. New zealand. The importance of the link is illustrated by its very high availability an average of $95 \%$ over the last 9 years at full load.

A cost benefit evaluation was carried out to determine the economics of earthquake strengthening of the resistors. The evaluation showed that the outage of the HVDC link caused by earthquake damage to the resistors would cost Electricorp many times more than the cost of earthquake strengthening the resistors [1].

A number of seismic strengthening methods were investigated.

The first method is to strengthen the resistors by increasing the strength of the support. The existing porcelain

Senior Engineer, DesignPower NZ,

P. 0. Box 668, Wellington,

New Zealand bushing, which forms the main body and support of the resistor, is not a standard off-the-shelf item.

To replace it with a stronger bushing to meet the design requirements would present a major design and manufacture problem to achieve the necessary acceleration withstand (about $3 \mathrm{~g}$ ) and require long and costly plant outages to dismantle and reassemble the resistors. The overall cost of this method would be prohibitively expensive.

The second method is to reduce the seismic loading on the resistor by using a baseisolation design. Elastomeric bearings with lead plugs were found to be unsuitable as the stiffness they provide was too high compared with the stiffness required by the rather light resistor, at $9370 \mathrm{~kg}$, to give the resistor the desired period shift.

A rolling or sliding mechanism is therefore more suitable for this light structure and various combinations of springs (steel, rubber) and energy absorbers (ductile, hydraulic) were studied.

In the scheme finally adopted, each resistor was lifted off its concrete support and mounted on a steel frame supported on 4 spherically-ended rollers. These were so proportioned that the natural period of the resistor, moving horizontally as a single body, was lengthened to about 1 second. Each frame is fitted with telescopic shock absorbers giving about $40 \%$ of critical damping.

Supported on the rollers, the resistor can be designed for a seismic design load of $0.4 \mathrm{~g}$ which is well within its seismic withstand capability.

\section{A GENERAL DESCRIPTION OF THE DESIGN}

The distance between the top and bottom spherical caps of the roller is shorter than the corresponding diameter of the spheres. Consequently, when the rollers are moved out of their equilibrium position, a moment is developed tending to return them 
to that position. This is similar to the action of a pendulum. Thus the whole resistor can move relative to the ground with a natural period determined by the roller geometry and with damping determined by horizontally mounted telescopic shock absorbers.

Guide-pins are provided at the centre of the top and bottom caps of the roller to prevent the rollers from sliding. Holding down coil springs are used to help resist overturning forces but not interfere with the motion of the resistor.

The general arrangement of the design is shown in Figs. 1 and 2 .

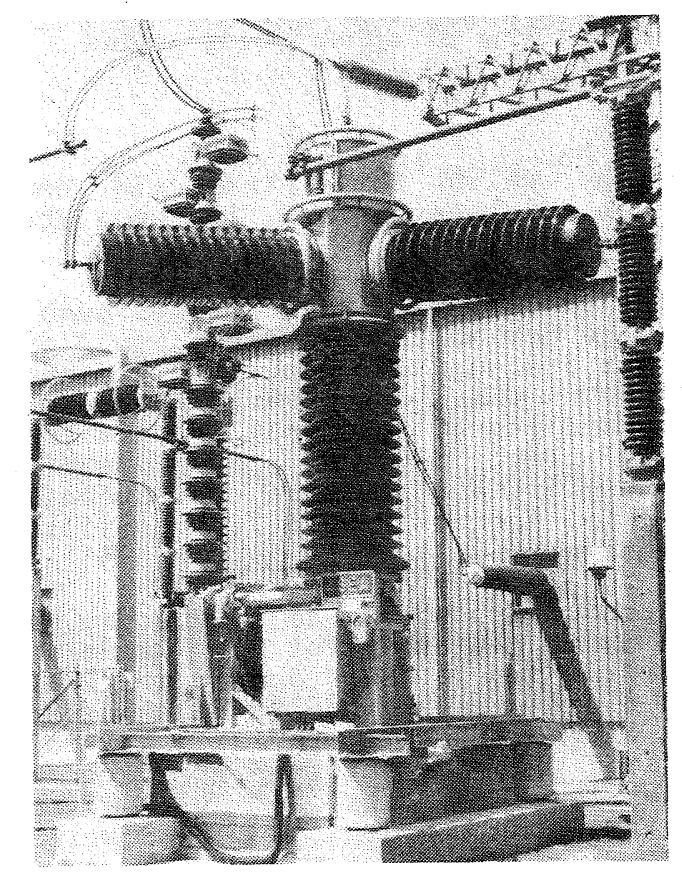

FIG. 1 - HVDC VALVE DAMPING RESISTOR ON A BASE ISOLATION DESIGN USING SPHERICALLY-ENDED ROLLERS

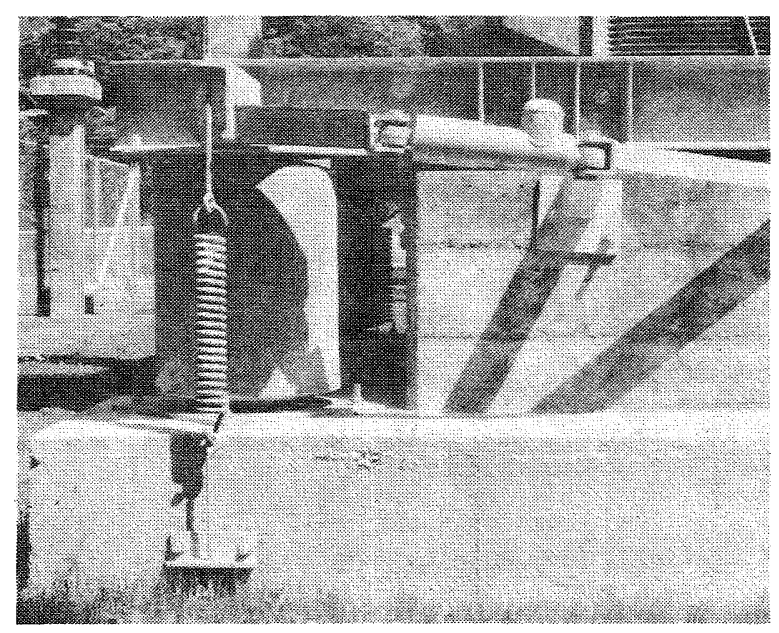

FIG. 2 - A CLOSE-UP VIEW OF THE ROLLER, SPRING AND SHOCK ABSORBER

\section{DYNAMIC CHARACTERISTICS OF THE ROLLER}

\section{The roller before the critical position}

When the roller is moved out of its rest or equilibrium position, a moment is developed tending to return it to that position. This moment can be expressed in terms of a restoring force, $F$.

For a given roller geometry and vertical load, $F$ varies almost linearly with the angle of rotation of the roller, $\beta$. F increases with $\beta$ until $\beta$ reaches a critical position of $\beta$ where $F$ is at a maximum. After $\beta, C F$ decreases with further rotation as shown in Fig. 3. A point will be reached when $F$ equals zero, beyond this point the roller will become unstable and collapse. The various positions of the roller are shown in Fig. 4.

The natural period, $T$, is, on the other hand, almost independent of the angle of rotation, and for a small $\beta, \mathrm{T}$ is determined by the geometry of the roller as illustrated below :

$M=$ mass of resistor plus support frame.

$\mathrm{W}=\mathrm{Mg}=$ dead weight or vertical load.

$\mathrm{R}=$ radius of the top and bottom caps of the roller.

$\mathrm{H}=$ total height of the roller.

From Fig. 4b:

$\mathrm{a}=$ distance between geometric centres

$=2 \mathrm{R}-\mathrm{H}$ when offset from the rest position.

$\mathrm{b}=$ horizontal distance between the geometric centres of the top and bottom caps.

$=(2 \mathrm{R}-\mathrm{H}) \sin \beta$

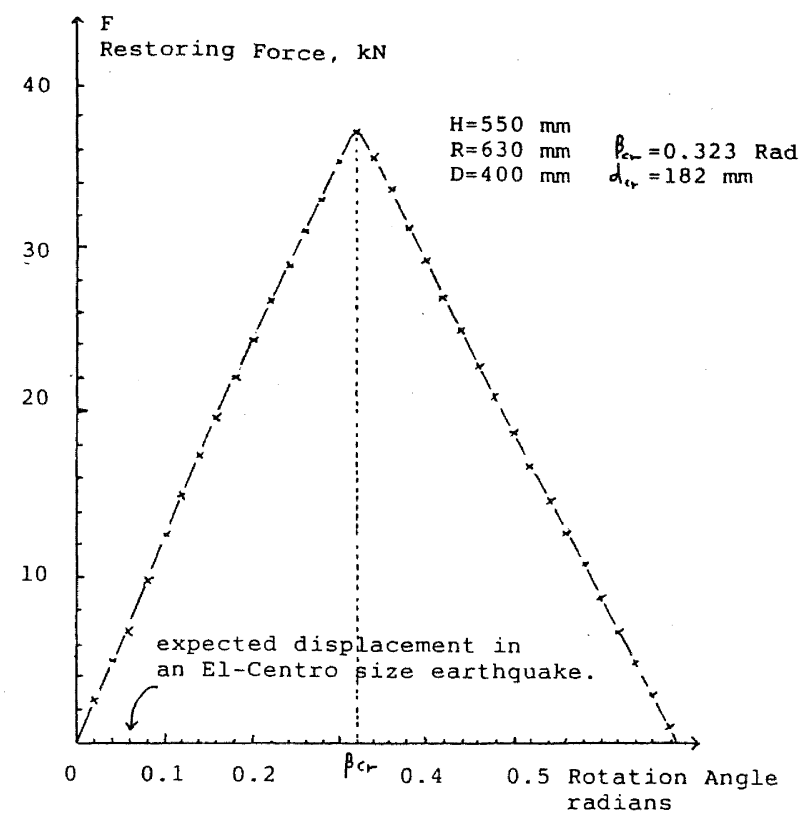

FIG. 3 - RESTORING FORCE VERSUS ROTATION ANGLE 


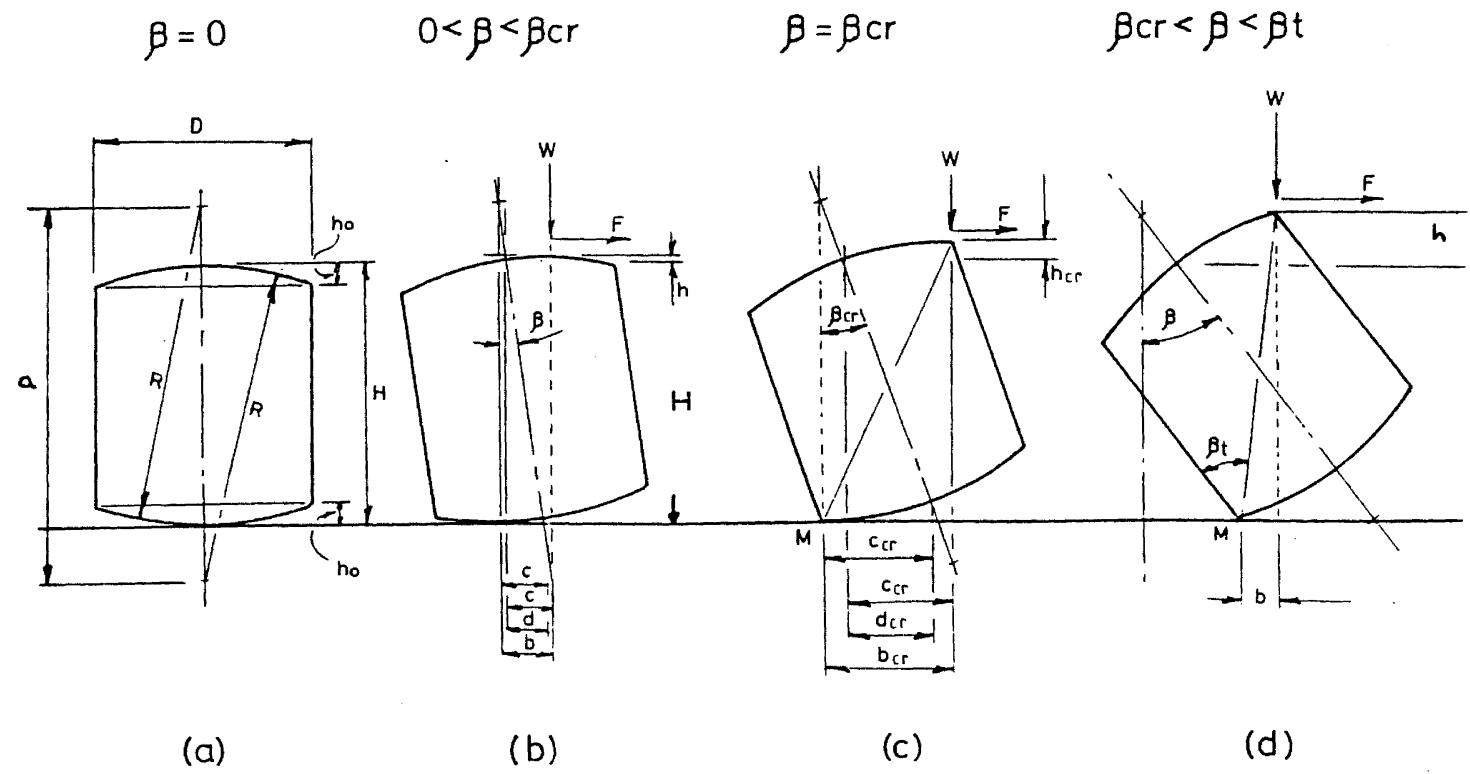

FIG. 4 - VARIOUS POSITIONS OF THE ROLLER

$c=$ horizontal movement of points of contact.

$=$ the length of the arc displacement of the top or bottom caps.

$=\mathrm{R} \beta$

$d=$ horizontal displacement of the frame supported by the rollers.

$=2 \mathrm{c}-\mathrm{b}$

$=2 \mathrm{R} \beta-(2 \mathrm{R}-\mathrm{H}) \sin \beta$

$\mathrm{h}=$ vertical lift of the frame supported by the rollers

= difference between the distance of two geometric centres at rest, $(2 \mathrm{R}-\mathrm{H})$ and at an angle $\beta,(2 \mathrm{R}-\mathrm{H}) \cos \beta$

$=(2 \mathrm{R}-\mathrm{H})(1-\cos \beta)$

Restoring moment $=\mathrm{Wb}$

and the equivalent horizontal force, $F$, which is required to offset the roller is:

$F(H+h)=W b$

The equivalent stiffness of the roller is: $\mathrm{K}=\mathrm{F} / \mathrm{d}$

For a $\operatorname{small} \beta, \cos \beta \approx 1$ and $\sin \beta \approx \beta$, hence

$$
\mathrm{K}=\mathrm{W}(2 \mathrm{R}-\mathrm{H}) / \mathrm{H}^{2}
$$

Therefore the natural period of the resistor supported on the rollers is:

$$
\begin{aligned}
\mathrm{T} & =2 \pi \sqrt{ }(\mathrm{M} / \mathrm{K}) \\
& =2 \pi \mathrm{H} / \sqrt{ }((2 \mathrm{R}-\mathrm{H}) \mathrm{g})
\end{aligned}
$$

which only depends on the geometry of the rollers.

To help resist the overturning moment, coil springs are used in the design. The effect is that coil springs add to the total restoring force, stiffen the structure slightly and reduce the natural period estimated by equation 9 .

\section{The roller at the critical position}

The roller reaches a critical position when it has rolled to the edge of the caps and the vertical load is now acting at the edge, Fig. $4 \mathrm{c}$.
At this position:

$$
\beta_{\mathrm{Cr}}=\sin ^{-1}(\mathrm{D} / 2 \mathrm{R})
$$

where $D$ is the diameter of the roller drum and the critical horizontal displacement, $\mathrm{d}_{\mathrm{cr} \boldsymbol{r}^{\prime}}$ is

$$
\mathrm{d}_{\mathrm{Cr}}=2 \mathrm{R} \beta_{\mathrm{Cr}}-(2 \mathrm{R}-\mathrm{H}) \sin \beta_{\mathrm{Cr}}
$$

The roller beyond the critical position

Beyond the critical position the roller no longer rolls but rotates about the edge of its bottom cap, point $M$ of Fig $4 \mathrm{~d}$. The moment arm, $b$, decreases with further rotation and hence the restoring moment does also.

A point will be reached when

$$
\begin{aligned}
& b=0 \\
& \beta=\tan ^{-1}\left(D /\left(H-2 h_{0}\right)\right)
\end{aligned}
$$

The restoring moment will be zero and any further rotation will cause a total collapse of the roller.

\section{SELECTION OF DESIGN PARAMETERS}

\section{Natural period and Roller geometry}

The natural period of the resistor rigidly mounted was tested at 0.28 secs. To avoid any dynamic amplification due to resonance, the rollers are designed such that the natural period of the resistor is lengthened by a factor of about four to 1 secs.

The ground conditions where the resistors are located (weathered greywacke at Haywards) are such that long-period earthouakes are unlikely to occur [2]. A one second design period is considered to be adequate to reduce the earthquake response of the resistor to an acceptable level. 
Having chosen the design period, the roller height, $H$, and the cap radius, $R$, can be calculated. The diameter of the roller, $D$, is determined from the critical horizontal displacement, $d_{c r}$. The thickness of the roller drum and caps are determined from a stress analysis using the finite element method.

\section{Overturning consideration}

The resistors are tall structures with a total height of about $5.6 \mathrm{~m}$ for the tallest one. The design calculations for the worst case have shown that the dead weight is not adequate to resist the overturning moment due to eartkquake forces. To increase the resistance to the overturning moment, coil springs attached to the support frame and the foundation are provided. The addition of the coil springs increases the horizontal stiffness of the whole structure and shortens the design natural period. As a result the geometry of the roller must be modified to allow for this factor.

\section{Base shear}

At the centre of the roller cap, a $30 \mathrm{~mm}$ diameter hole is provided. Into this hole is a guide-pin with a profile such that the roller is in constant contact with the guide-pin when it rolls. Two guide-pins are provided, one for the top cap and one for the bottom cap. Each is welded to a steel plate. The top plate is bolted to the support frame and the bottom plate is bolted to the foundation. The guide-pins are designed to take the shear load and to prevent the rollers from sliding.

\section{Damping}

This design is based on the use of single body acceleration and displacement response spectra for bodies with supports providing high levels of damping. At 1 secs natural period, the resistor is expected to move by a significant amount during a strong earthquake. To limit this displacement and to help reducing the earthquake response, damping must be provided. viscous damping in the form of telescopic shock absorbers is chosen because they are commercially available, their damping characteristics are known and are reasonably linear with velocity. If necessary, their performance can be tested quite easily.

A damping of $40 \%$ critical was selected because larger values gave little reduction in response. The size of the shock absorbers can be calculated using simple equations for damping rate and stiffness.

\section{PROTOTYPE TESTING}

A prototype of the rollers and support frame was fabricated by the canterbury Engineering Company of christchurch. Concrete blocks were used as a test load to simulate the dead weight of the resistor. The total height of the blocks was made to be the same as the tallest resistor so that the overturning moment could be checked. The set-up for the test is shown in Fig. 5 .

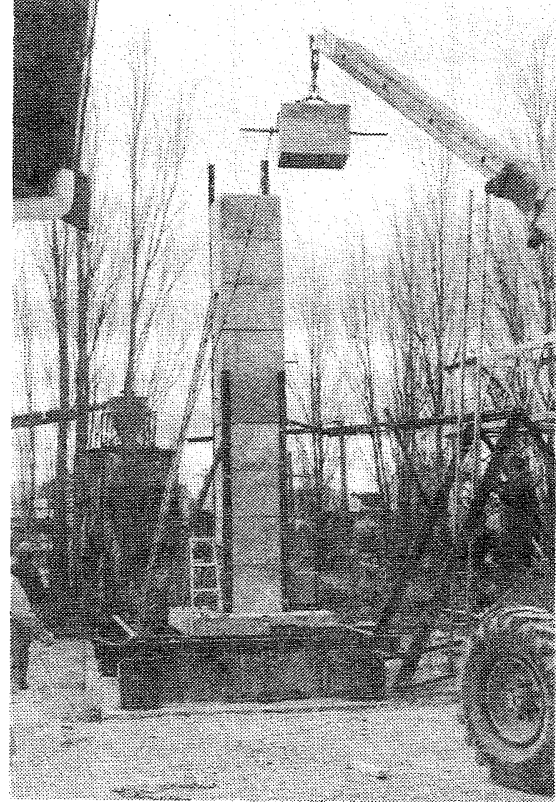

FIG. 5 - SETTING UP FOR PERFORMANCE TESTING. CONCRETE BLOCKS ARE USED AS THE TEST LOAD.

Three types of test were carried out:

a) Pull-and-release test: the test load was pulled horizontaliy at the centre of gravity by a hydraulic ram and released at a predetermined load. The release mechanism was provided by a tensile rod designed to break at a given load. To check the performance of the rollers in the rotational mode, a pull was applied at a 45 degree angle to the transverse direction of symmetry of the resistor.

b) Shaking test using a shaker mounted on top of the test load. Sinusoidal exciting force at different frequencies was applied in both transverse and longitudinal direction. The shaker was supplied by the Civil Engineering Department of the University of Canterbury.

c) Static overturning test: a horizontal load was applied at the centre of gravity and increased until a gap appeared between the support frame and the top cap of the roller.

Accelerometers and displacement transducers were used to obtain acceleration and displacement records.

Test results showed that the prototype performed well and met most of the design requirements. However, the natural period at low amplitudes of vibration was found to be lower than expected. This was because, at low amplitudes, the rollers rocked about the guide-pin rather than rolled as assumed in the original analysis. The problem was solved simply by reducing the diameter of the guide-pin from $50 \mathrm{~mm}$ to $30 \mathrm{~mm}$ and increasing the height of the rollers 
from $500 \mathrm{~mm}$ to $550 \mathrm{~mm}$. The result is a reduction of rocking amplitude and an increase in the natural period of the resistor.

With these changes, the following test results were obtained:

Natural periods $=1.15 \mathrm{~s}$ (for amplitudes of vibration greater than the radius of the guide pin of $15 \mathrm{~mm}$ )

$=0.83 \mathrm{~s}$ (for amplitudes

of vibration less than the radius of the guide pin of $15 \mathrm{~mm}$ )

The results compared with $1.3 \mathrm{~s}$ (calculated from equation 9) and $1.23 \mathrm{~s}$ (calculated with the effect of holding down springs included).

Using the telescopic shock absorbers specified at $32.6 \%$ of critical damping, a value of $34 \%$ was obtained. (The $40 \%$ shock absorbers selected for the design were not available at the time of tests).

\section{ERECTION}

To keep the shutdown time required for the erection to a minimum, the new foundation for the rollers was built well before the annual shutdown of the HVDC link in November/December $1984 . \quad$ The rollers and steel work were fabricated and galvanised ready to be installed.

The erection took very little time, some minor problems were encountered in the drilling of holes but overall the erection was straight forward.

Existing rigid connections were replaced with more flexible connections to allow for up to $150 \mathrm{~mm}$ movement.

\section{CONCLUSIONS}

Supported on rollers, the valve damping resistors are expected to withstand earthquakes several times stronger than the El Centro 1940 earthquake.

The use of spherically-ended rollers with shock absorbers as a base-isolation method has several advantages:

a) The design analysis is relatively simple.

b) The designer can control and have confidence in the performance of the rollers without having to carry out exhaustive testing to establish the performance parameters.

c) For a seismic strength upgrading design, the rollers are simple to install and thus the outage time required for erection can be kept to a minimum. For an electrical system, this outage time is critical and often determines the economics of earthquake strengthening.

d) The rollers are relatively cheap and easy to fabricate. overturning is a major design consideration when using the rollers, especially for tall and slender structures. Positive restraints, in the form of coil springs must be provided, or the rollers must be spaced sufficiently far apart so that the dead weight can be relied upon to resist overturning.

\section{ACKNOWLEDGEMENTS}

The basic design for incorporating spherically-ended rollers in this base isolation scheme were developed by New Zealand Electricity Department staff while $\mathrm{Mr}$ H.C Hitchcock was Senior Research Engineer and the author wishes to thank him for assisting with background information for this paper.

The author also thanks the General Manager of DesignPower NZ for permission to publish this paper.

\section{REFERENCES}

1. Pham, L.T., Rutledge,A.L, "Earthquake Protection Upgrading of New Zealand's International Conference on $A C / D C$ Power Transmission, London, Sept 1985.

2. Peek,R., "Estimation of Seismic Risk for New Zealand; a Seismicity Model and Preliminary Design Spectra", Dept. of Civil Engineering, Canterbury University, Research Report No. 80-21. 